Fear of falling

misperformance and re-enactment in national spectacle

Borggreen, Gunhild Ravn

Published in:

Performance Research: a journal of the performing arts

DOI:

$10.1080 / 13528165.2010 .490429$

Publication date:

2010

Citation for published version (APA):

Borggreen, G. R. (2010). Fear of falling: misperformance and re-enactment in national spectacle. Performance

Research: a journal of the performing arts, 15(2), 44-49. https://doi.org/10.1080/13528165.2010.490429 
This article was downloaded by: [Borggreen, Gunhild][DEFF]

On: 7 July 2010

Access details: Access Details: [subscription number 789685088]

Publisher Routledge

Informa Ltd Registered in England and Wales Registered Number: 1072954 Registered office: Mortimer House, 3741 Mortimer Street, London W1T 3JH, UK

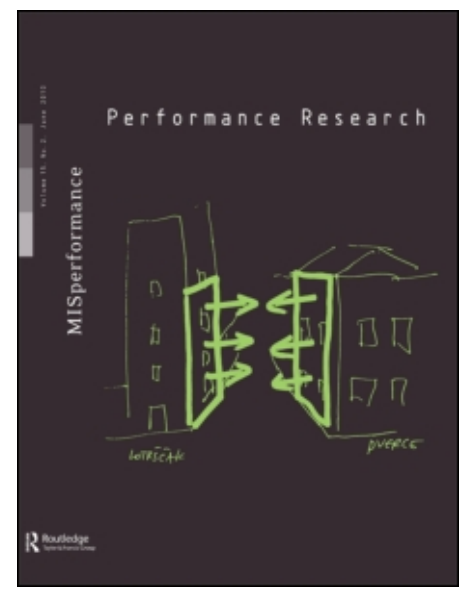

\section{Performance Research}

Publication details, including instructions for authors and subscription information:

http://www.informaworld.com/smpp/title content=t716100720

\section{Fear of Falling: Misperformance and re-enactment in national spectacle}

Gunhild Borggreen

Online publication date: 07 June 2010

To cite this Article Borggreen, Gunhild(2010) 'Fear of Falling: Misperformance and re-enactment in national spectacle', Performance Research, 15: 2, $44-49$

To link to this Article: DOI: 10.1080/13528165.2010.490429

URL: http://dx.doi.org/10.1080/13528165.2010.490429

\section{PLEASE SCROLL DOWN FOR ARTICLE}

Full terms and conditions of use: http://www.informaworld.com/terms-and-conditions-of-access.pdf

This article may be used for research, teaching and private study purposes. Any substantial or systematic reproduction, re-distribution, re-selling, loan or sub-licensing, systematic supply or distribution in any form to anyone is expressly forbidden.

The publisher does not give any warranty express or implied or make any representation that the contents will be complete or accurate or up to date. The accuracy of any instructions, formulae and drug doses should be independently verified with primary sources. The publisher shall not be liable for any loss, actions, claims, proceedings, demand or costs or damages whatsoever or howsoever caused arising directly or indirectly in connection with or arising out of the use of this material. 


\title{
Fear of Falling Misperformance and re-enactment in national spectacle
}

\author{
G U N H I L D B O RG GRE EN
} ${ }^{1}$ Japanese names are
given here family name
first.
2003 was a decisive year for the contemporary visual artist Yanobe Kenji. ${ }^{1}$ This we may learn from a recollection by Yanobe in a recent interview:

I decided never to wear my signature Atom Suit
again. I completely cleansed my system of
everything inside me, of every tool I had ever used
in life, and at the moment when I reset my soul,
I got really worried if anything at all would ever
enter my imagination again. I even thought I would
stop being an artist.
(Yanobe 20o8: 244)

These strong emotions were a result of several changes in Yanobe's personal life as well as the geopolitical situation of the world, all of which were reflected in an extensive art project that he staged in 2003 at the site of the former Expo 70 in the outskirts of Osaka. Yanobe's art project was a confrontation with his own romantic ideal and artistic practice, in which he had previously been performing what he identifies as 'the protection of my own body' (2008: 246) but which he had now found challenged by reality. In the quote above, Yanobe acknowledges a misperformance, as if the basic tool for an artist, the imagination, would stop working and he would cease being an artist altogether. But what exactly caused this misperformance and the subsequent abolishment of his visual and conceptual art signature, the Atom Suit?

Responding to the theme of misperformance, this text will try to locate the particular situation in which Yanobe Kenji misses his trajectory and in broader sense will discuss key elements in regards to visual arts related to issues of social and political concern. My point of departure is the national performance of post-war Japan, which has been extremely successful in mainstreaming selected elements of cultural products and identities, resulting in distorted images of Japanese culture and visual arts both in and outside Japan. However, part of the Japanese cultural landscape, which is much less known, is the recent use of art and culture within explicit acts of political protests. As Môri Yoshitaka points out, many young activists in Japan are equally motivated by politics as by artistic practice. Moreover, they often have a keen interest in historical predecessors in the 196os and engage in subversive re-enactments of political activism as performance (Môri 2005: 19).

My focus will be on the slippage of iteration that takes place between two separate but interconnected fields: political activism that relies on misperformance as a way of interfering with panoptic power structures on the one hand and artistic performance embodied in physical engagement and the fear of falling on the other. After a brief introduction to the contemporary Japanese artist Yanobe Kenji, I will focus on Expo 70, the first world exposition in Japan, as a spectacle that reinforced national performance. This leads to a discussion of political movements in Japan in the 196os and a focus on anti-Expo activism as misperformance. The next part will deal with Yanobe Kenji's present-day re-enactment related to Expo 70. Finally, I will discuss this two-fold misperformance in light of Yanobe's own 
artistic archive, and my analysis will conclude with how this double misperformance brings about a new kind of merger of political and personal artistic practice.

\section{YANOBE KENJI}

The contemporary Japanese artist Yanobe Kenji is often associated with the neo-pop art movement, and references to popular culture such as manga (comic series) or otaku nerd subculture in Yanobe's art aligns him with a number of other contemporary artists in Japan, such as Murakami Takashi and Nara Yoshitomo. However, Yanobe's works also include complex layers of references to historical memory and social critique. As I have argued elsewhere (Borggreen 2006), many of Yanobe's works are constructed as 'wearable sculpture' that can be controlled and manipulated by a human being inside, and at the same time in a humoristic and slightly ironic manner offers a kind of protection or shield to ward off dangers from the outside. This can be seen in works such as Tanking Machine from 1990, a huge container filled with warm water into which audience members in the gallery can submerge themselves as if 'returning to the womb', or Emergency Escape Pods from 1996, designed as mobile protection chambers equipped with emergency rations for otaku survival, including water, candy and comic books.

One of Yanobe's many art projects is the Atom Suit Project, which was conceived around 1995 and consists of a yellow protection suit with helmet and Geiger-Müller counters placed around the suit at sensible body parts. Based on a character related to the world of manga, Yanobe creates his own artistic character by applying this Atom Suit as his trademark. One part of Yanobe's Atom Suit Project was to visit the abandoned city of Pripyat near Chernobyl, where one of the most serious accidents at a nuclear power plant occurred in 1986. In 1997 Yanobe created a series of photographs of himself dressed in his yellow protection suit, staged at various decayed and deserted sites in Pripyat.
This is where Yanobe develops his notion of mirai no haikyo, ruins of the future. The concept of ruins of the future signifies Yanobe's way of investigating, from the present day perspective, how a narrative of the future was imagined and constructed in the past. He investigates how ideas of utopia may turn into delusions. In the case of Chernobyl, he deconstructs the dream of unlimited energy resources by pointing out the literal and metaphorical ruins resulting from the catastrophe when technology fails.

\section{EXPO 70 AS A SPECTACLE}

After this brief introduction, I will go back in time to the world exposition held in Osaka in 1970, also known as Expo 70. This was the first expo held outside the Western world. The event marked the highlight of a national narrative that emphasized Japan's role as the spearhead of 'progress and harmony for mankind', which was the slogan of Expo 70 (Official Report 1972: 11). During the 1960 s Japan performed what was dubbed an 'economic miracle', exceeding the pre-war level of industry and trade. The world exposition in Japan in 1970 was visited by 64 million people during the six-month period, and it boosted the economic growth even further into the 1970s. Developments of high technology, such as robots, communication systems and a popular ultrasonic bathtub, were emphasized as areas where Japan as a nation could contribute to a global future. The traumatic experience from the atomic bombs dropped by the USA on Hiroshima and Nagasaki in 1945 was transformed into a positive affirmation towards a peaceful application of nuclear power as energy resource. New and groundbreaking principles in architecture and design were displayed, and the visual layout of the expo site as well as the numerous pavilions, buildings and towers signified a brightly coloured and optimistic version of the future.

The most significant and symbolic structure was the Tower of the Sun, designed by the artist Okamoto Tarô, and placed at the central Expo 


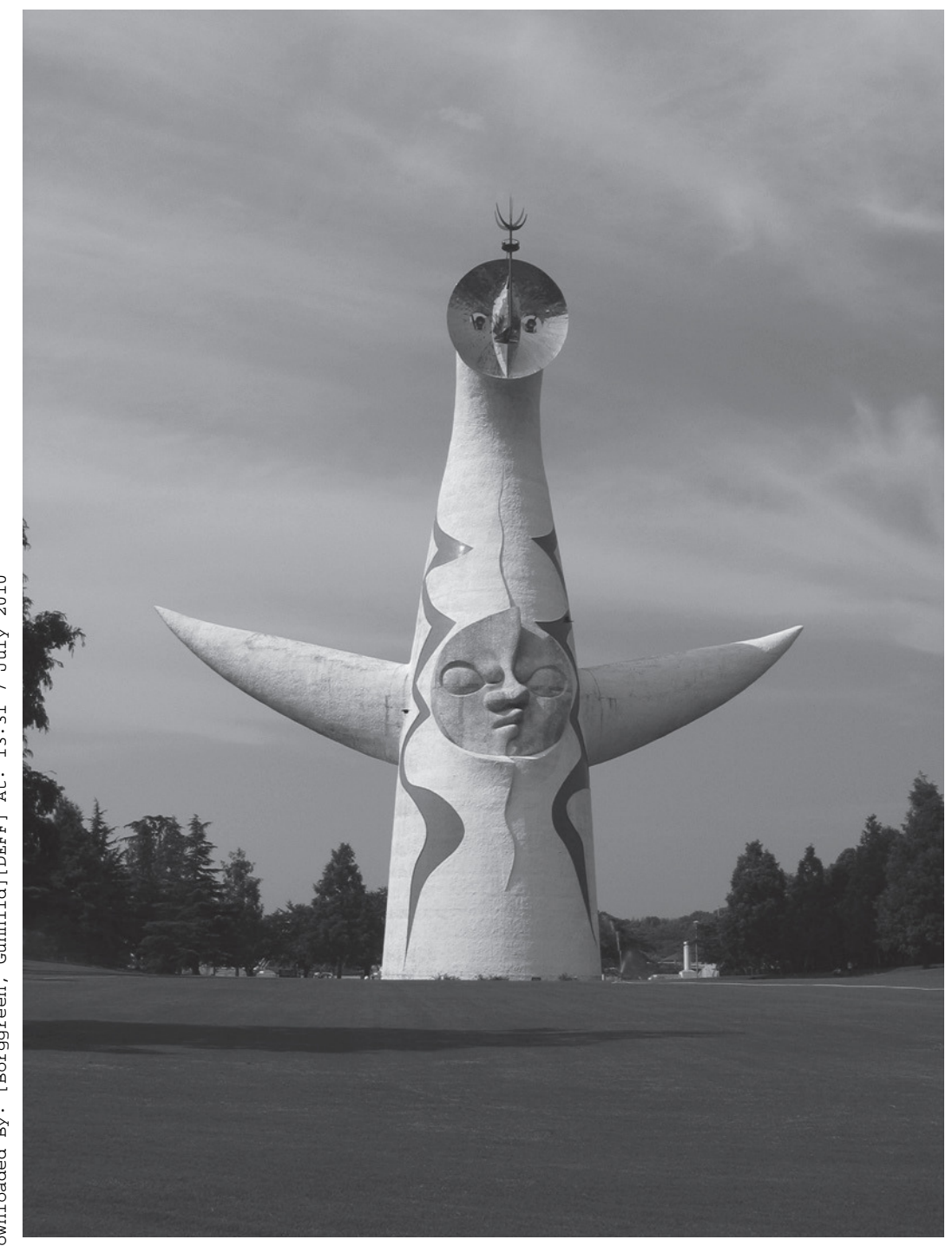

- Okamoto Tarô, Tower of the Sun, 1970.
ANTI-EXPO ACTIVISM AS

MISPERFORMANCE

The optimistic version of the future promoted through Expo 70 was, however, contested at the time by protest movements and antiwar groups that flourished in Japan during the 1950s and 1960 s. The AMPO movement had organized large demonstrations against the political alliance between USA and Japan manifested in the US-Japan Security Treaty. Expo 70 became a concrete symbolic event against which various groups and individual of activists and artists could protest the official narrative of the nation and try to promote alternative visions for the future. The art group Zero Jigen, for example, launched a series of anti-Expo protest actions in several cities throughout Japan in 1969, wearing helmets and marching with raised hands in a parody of military processions. Within the framework of Michel de Certeau's strategy and tactics, strategy is the 'mastery of places through sight', where authorities construct spaces of panoptic practice from which objects can be observed, measured and controlled within the scope of vision (Certeau 1984: 36]. Strategy legitimates power of knowledge. A tactic, on the other hand, is a mobile, isolated and spontaneous action that can never keep what is won. A tactic is deliberate misperformance that creates fragments, cross-cuts and cracks in the framework of the system. As Peter Eckersall has pointed out, many of the activist enactments were played out as tactics in the Certeauvian sense, miming everyday practices but with distinct and deliberate reversals of social norms of behaviour, such as crawling on the ground when they should be walking straight up, walking naked through shopping malls when they should be fully dressed, or wearing business suits in a public bath where they were supposed to be naked (Eckersall and Borggreen 2007). In 1970 J Japan, anti-Expo protests were linked to student movements and included a tactical invasion of the panoptic centre of powerholders, as when a group of naked Zero Jigen events took place. The Tower of the Sun was built into the structure of a large roof covering the entire Expo Plaza, with an opening in the middle, allowing the golden mask of the Tower of the Sun to protrude into the sky. As Thomas Havens points out, the official participation of Okamoto Tarô and many other avant-garde artists in Expo 70 was subject to heated debates at the time, and Okamoto's tower was both admired and ridiculed by other artists (Havens 2006: 213-14). Today, the Tower of the Sun is one of the few remaining monuments of Expo 70 left in Osaka. 
members climbed the roof of a building at Kyoto University and for a brief moment appropriated, or hijacked, the symbolic vision of power.

One of the most spectacular single events of protest during the Expo happened on 26 April. Satô Hideo, a young activist from Beheiren, an anti-Vietnam War movement, climbed into the Tower of the Sun and ventured all the way to the extreme top of the tower, exited the tower structure and climbed out into the eye socket of the Golden mask of the tower. Occupying the eye of the central symbol of Expo 7o for almost a week without food, Satô Hideo captured the attention of everyone at the Expo, including the media. Several newspapers featured the story on the front pages of what became known as the Eyeball Man. Again, this specific action may be seen as a tactic invasion of the power-holder's high point, momentary and impermanent, a spontaneous and un-mappable form of subversion, embodying and making himself visible at the scopic centre of official Expo 70. Clearly, the Eyeball Man was trespassing and hereby misperforming a sense of normative behaviour, and he was wearing a helmet with the characters Sekigun, Red Army, a name that many in Japan would associate with the hijacking of a Japan Airlines flight only a few months earlier. But at the same time, the Eyeball Man's action appeared harmless, humorous and even friendly, as he would smile and wave to the crowds staring up from below. By the time Satô Hideo eventually did come down on 3 May and was arrested by the police, the media had invented a pun on the English word 'hijack' and dubbed the event 'eye-jack' (aijakku). According to Satô's later recollection of the event, his happening was characteristic of the Beheiren movement's non-violent policy and its emphasis on action rather than words (Aoki 2005). But behind this was a dead-serious activist approach: committing himself in what was in reality a hunger strike, the Eyeball Man was allegedly ready to die for the cause. And the non-violent aspect could only be claimed as long as the Eyeball Man did not fall down.
YANOBE KENJI'S RE-ENACTMENT

Yanobe Kenji grew up in Osaka, and although he did not visit Expo 70 himself as a child, he saw through the fence how large machines and bulldozers demolished the many buildings, robots and infrastructure of the Expo site afterwards. After his intervention in Chernobyl, Yanobe revisits the former site of Expo 70 dressed in the yellow protection suit, in another investigation of the ruins of the future. In 2003, more than thirty years after the eye-jack event at Expo 70, Yanobe re-enacts the Eyeball Man's happening and climbs the stairways inside of the Tower of the Sun to find the narrow passageway at the top leading to the Golden Mask. Yanobe's trespassing was documented on video, and it shows the artist struggle his way through the hatch and cling to the large lamp in the eye socket while a strong wind threatens to pull him down to the ground (Aoki 2005).

Yanobe Kenji appears to be fascinated by the radical dimension of Satô Hideo's action at Expo 70. Yanobe may have felt a kind of affinity with the Eyeball Man in his intervention with the official Expo version of the future. The Eyeball Man had climbed the symbolic Tower of the Sun and had found what Yanobe terms 'another exit to the future'. Referring to elements inside the Tower of the Sun, Yanobe accounts:

I wanted to see the potential for a breakthrough to the future, just as the Eyeball Man, who had travelled through time by climbing through the period of evolution of life, saw the sky of the future open before him. What indeed could be seen now through that giant eye? (Ôba 2005: 107)

Yanobe's re-enactment project included the difficult task of locating Satô Hideo, the Eyeball Man, many years later. A conversation between Yanobe and Satô was recorded on video, and here yet another dimension to Yanobe's concept of ruins of the future is apparent. In the video documentation, Yanobe draws a direct parallel between the Vietnam War in the 196os and the invasion by the United States into Iraq, which had 


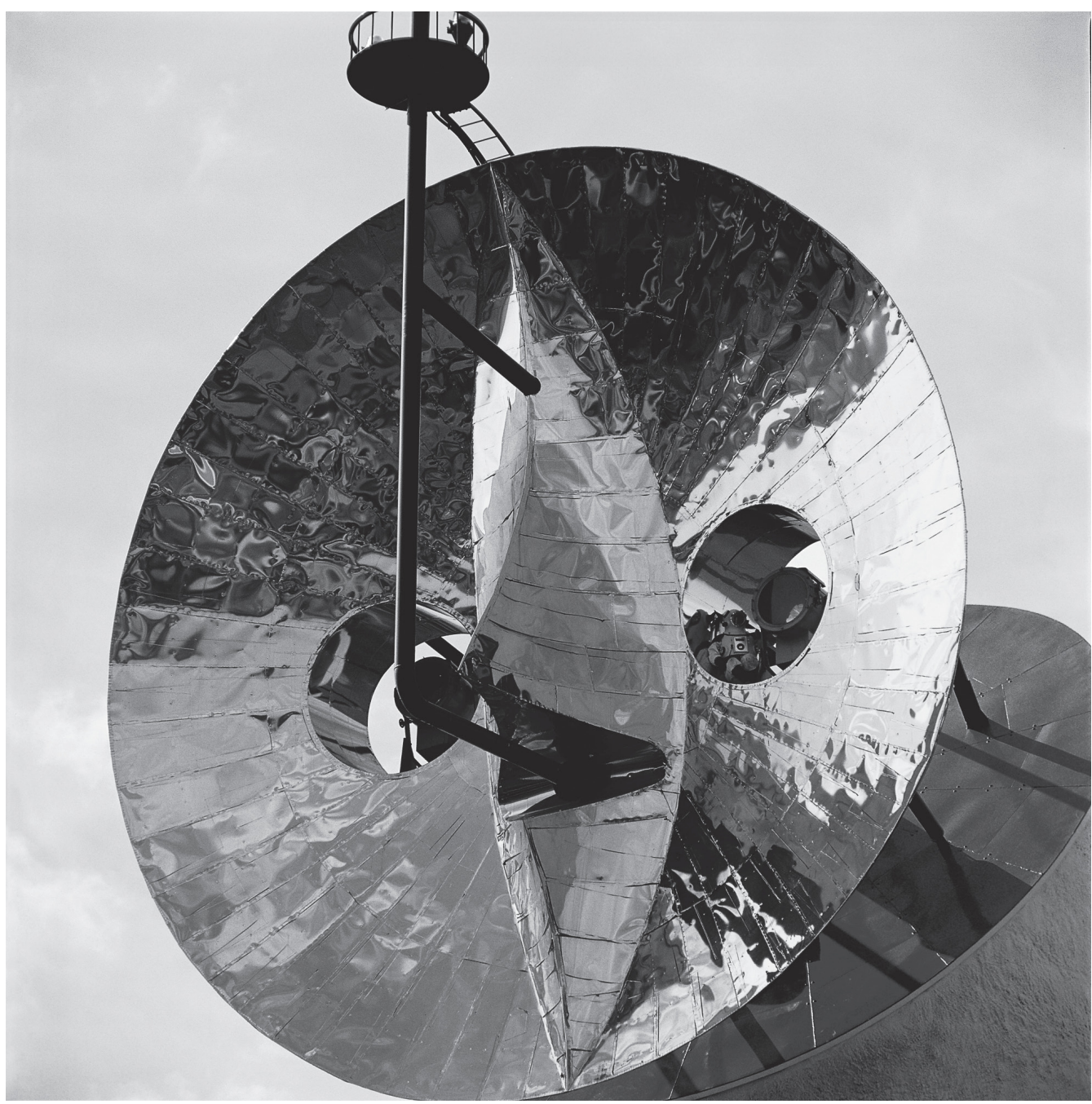

taken place only a short time before his conversation with the Eyeball Man took place in March 2003.

This indicates a re-interpretation of the ideological perspectives of the anti-war movements in the 196os. The anti-war movements protested against Japan's alliance with USA that included American troops being sent off to Vietnam from military bases on Japanese ground - at the time this was seen by many as double standards to Article 9 of the post-war Japanese constitution, which ruled out sending troops abroad. The topic was a major issue again in Japan in 2003, where heated debates focused on whether or not Japan should send troops to Iraq as an ally of the United States and for what purpose. By referring to this issue of contemporary war in the conversation with the Eyeball Man, Yanobe seems to be voicing political concern in relation to peace-keeping issues and Japan's role on the global scene. By re-staging a protest from 1970, Yanobe creates new meaning of current discussions and signifies the return to political consciousness in the contemporary art scene in Japan.

TWO-FOLD MISPERFORMANCE?

Yanobe's re-enactment draws upon and questions the archives of collective memory constructed through the idea of a national future envisioned in Expo 7o. He draws upon the archives of his own childhood, and he combines these references of delusion into the misperformance of the 
Eyeball Man - a tactic that, however significant at the time, did not in the end change Japan's official policy in regards to international war-related activities. Yanobe's re-enactment may point to this political perspective, but there is still a major difference between the Eyeball Man's political activism and Yanobe's artistic practice. Somehow, Yanobe misperforms the misperformance. So the question remains: what did Yanobe actually see through that giant eye of the Golden Mask?

I think Yanobe was struck by reality. Overwhelmed by the fear of falling. Yanobe's whole Atom Suit Project was well-conceived as representation and performance, and the admiration for the Eyeball Man he expresses in the video is purely abstract and theoretical, until the very moment when Yanobe himself exits the narrow hatch and finds himself challenged by a life-threatening situation - a sense of real danger, of bodily commitment, of putting his life at stake - and realizes that he had not at all been prepared for this confrontation with unmediated risk. It echoes Yanobe's experience in Pripyat in 1997 where he suddenly, unexpectedly, met a young boy and a number of other people who lived their real, everyday lives in constant radioactive contamination. Yanobe admits that 'the romantic fantasy that I had of walking around the ruins in my Atom Suit was completely destroyed when I faced the reality of the place' (2008: 245). Yanobe interacted with the boy, but he could not make himself take off his yellow protection suit. In fact, Yanobe did not show these photos in public for a number of years until he came to terms with the fact that reality overwhelmed his artistic and somewhat romantic notion of delusion. There is always something new growing up from the ruins of the future.

Here in the eye of the Golden Mask, reality again had an impact on the artist. As if Yanobe through the panoptic view finally could grasp his own artistic origin embodied in the former site of Expo 7o. After Yanobe had climbed back down from the Tower of the Sun, he took off his yellow protection suit and abandoned his trademark character, never to wear it again. Just as the national narrative of art and culture will always be torn down and re-created at other localities, artistic and activist interventions re-enact the archives of protest but do so at a new site, in another context. The two-fold misperformance points out the possibilities and necessities of such transitions.

\section{REFERENCES}

Aoki Kenji (2005) Megalomania, Kenji Yanobe Document (DVD), Kyoto: Seigensha Art Publishing. Borggreen, Gunhild (2006) 'Ruins of the Future: Yanobe Kenji revisits Expo 7o', Performance Paradigm: Journal of Performance and Contemporary Culture, 2, and in Edward Scheer and Peter Eckersall (eds) The Ends of the 6os: Performance, media and contemporary culture, Sydney: University of New South Wales, pp. 65-78.

Certeau, Michel de (1984) The Practice of Everyday Life, Berkeley: University of California Press

Eckersall, Peter and Borggreen, Gunhild (2007) 'Radical Bodies in the 196os Cultural Space', presentation at Nordic Association for Japanese and Korean Studies (NAJAKS) conference, Copenhagen, 24-26 August.

Havens, Thomas R. H. (2006) Radicals and Realists in the Japanese Nonverbal Arts: The avant-garde rejection of modernism, Honolulu: University of Hawaii Press. Môri Yoshitaka (2005) 'Culture = Politics: The emergence of new cultural forms of protest in the age of freeter', Inter-Asia Cultural Studies, 6(1): 17-29.

Nakawada, Minami and Atmosphere Ltd (2005) Expo '7o: Kyôgaku! Ôsaka bankoku hakurankai no subete, Tokyo: Diamond.

Ôba Miwa, (2005) Kenji Yanobe 1969-2005, Kyoto: Seigensha Art Publishing

Official Report of the Japan World Exposition, Osaka, 1970 (1972), Osaka: Commemorative Association for the Japan World Exposition 1970.

Yanobe Kenji (2008) 'A Time Machine to the End of the Future', in Christopher Phillips and Noriko Fuku (eds) Heavy Light: Recent photography and video from Japan, New York: International Center of Photography, pp. 242-54. 